\title{
Creating frog heart as an organ: in vitro-induced heart functions as a circulatory organ in vivo
}

\author{
MASAYOSHI KINOSHITA 1,2,\#, TAKASHI ARIIZUMI ${ }^{3, \#, ~ S H I N S U K E ~ Y U A S A ~} 1,2$, SHUNICHIROU MIYOSHI2,

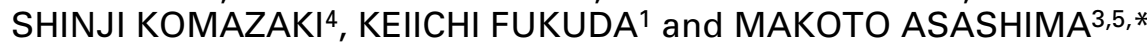 \\ ${ }^{1}$ Department of Regenerative Medicine and Advanced Cardiac Therapeutics, ${ }^{2}$ Division of Cardiology, \\ Department of Internal Medicine, Keio University School of Medicine, Tokyo, ${ }^{3}$ Department of Life Sciences \\ (Biology), Graduate School of Arts and Sciences, The University of Tokyo, Tokyo, ${ }^{4}$ Department of Anatomy, \\ Saitama Medical School, Saitama and ${ }^{5}$ Organ Development Research Laboratory, National Institute of \\ Advanced Industrial Science and Technology (AIST), Ibaraki, Japan.
}

\begin{abstract}
Cardiomyocytes have been induced from various pluripotent cells, such as embryonic stem cells and myeloid stem cells; however, the generation of cardiac tissues beyond twodimensional cell-sheets has not been reported. Creating higher order, three-dimensional structures that are unique to heart is the long-awaited next step in realizing cardiac regenerative medicine. We have previously shown that cardiomyocytes can be induced in vitro from undifferentiated cells (animal caps) excised from Xenopus embryos. Cardiomyocytes were induced by first dissociating the animal caps and then reaggregating them following treatment with activin. Here, we describe an interesting method for creating a complete ectopic heart in vivo, involving the introduction of in vitro-created tissue during early embryogenesis. Thus, animal cap reaggregates were transplanted into the abdomen of late-neurula-stage embryos, resulting in two-chambered hearts being formed. The dual-heart larvae matured into adult animals with transplanted hearts intact. Involvement of transplanted hearts in systemic circulation was demonstrated. Moreover, the ectopic hearts possessed higher order structures such as atrium and ventricle, and were morphologically, histologically, and electrophysiologically identical to original hearts. This system should facilitate the study of heart organogenesis and may promote a shift from tissue to organ engineering for clinical applications.
\end{abstract}

KEY WORDS: activin, animal cap, cardiogenesis, organ engineering, Xenopus laevis

\section{Introduction}

The African clawed frog Xenopus laevis develops outside the maternal corpus, making development easy to observe. This organism also follows the same developmental pattern as humans, thus offering a very useful model for early organogenesis and particularly those aspects related to cardiac research (Ariizumi and Asashima 2001; Warkman and Kreig 2007; Asashima et al. 2009). A wealth of research is ongoing into myocardial regeneration using cell types such as embryonic stem (ES) cells (Fukuda and Yuasa 2006; Asashima et al. 2008) and myeloid stem cells (Dengler and Katus 2002). More recently, induced pluripotent stem (iPS) cells have emerged as a potent candidate for myocar- dial regeneration (Mauritz et al. 2008). Numerous studies have transplanted myocardial cells generated from such cell types into hearts that have undergone myocardial infarction to improve function (Caspi et al. 2007). It is apparent from the collective results that cells used to induce myocardial cells have now been sourced from higher-order animals ranging from mice to humans, and that cardiac tissue engineering has already entered a mature stage, with breakthrough experimental systems under development. An important question regarding cardiac regeneration is

Abbreviations used in this paper: ES, embryonic stem; iPS, induced pluripotent stem (cell).

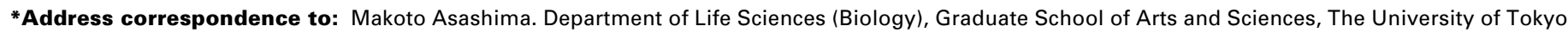
Tokyo, Japan. Fax: +81-3-5454-6998. e-mail: asashi@bio.c.u-tokyo.ac.jp
}

\#Note: M.K. and T.A. contributed equally to this work.

Supplementary Material for this paper (3 movies) is available at: http://dx.doi.org/10.1387/ijdb.093036mk 
whether an entire heart could be regenerated rather than simply aggregating cells that exhibit cardiac function. We attempted to address this issue using Xenopus laevis as an animal model of cardiogenesis. Success in this endeavour would represent a shift from tissue to organ engineering.

Undifferentiated cells collectively known as the animal cap are present in the blastula of Xenopus laevis. This region comprises approximately 1,000 cells and is capable of inducing differentiation of myocardial cells following activin activation (Ariizumi et al. 1996) or overexpression of factors such as GATA4 (Latinkic et al. 2003) and Wnt11 (Pandur et al. 2002). In all such investigations, however, the induction rate for myocardial cells was by no means high, and induced tissues did not structurally resemble the heart as an organ. We recently established an experimental system that induces myocardial cells with near to $100 \%$ probability, using a novel procedure for temporarily dissociating cells before the animal cap is treated with activin (Ariizumi et al. 2003). When these cells are cultivated, they do not simply form a mass of myocardial cells, but rather take on a tubular structure. In the present investigation, animal caps for which cardiac differentiation was induced were transplanted ectopically into other neurulae. The transplanted frogs were then examined for one year after transplantation for the presence of higher order heart structures and for the potential function of such ectopic organs in the systemic circulation. Analysis involved immunohistochemical, electron microscopic, echocardiographic, and electrophysiological examinations.

\section{Results}

\section{In vitro cardiomyocyte induction and in vivo ec- topic heart formation}

We first induced in vitroheart formation using Xenopus animal cap cells (Fig. 1A). Blastula animal caps did not differentiate into beating cardiomyocytes after treatment with $100 \mathrm{ng} / \mathrm{ml}$ of activin for 5h; however, upon dissociation and subsequent treatment with activin to reassemble the animal cap cells, nearly all reaggregates $(94.7 \%, 36$ of 38 cases) began beating on culture day 2 , which is comparable timing-wise to the initiation of heart beating in normal embryos (st. 35; Nieuwkoop and Faber 1956).

To investigate whether the activin-treated reaggregates (cardiomyocyte primordium) could form heart in vivo, these primordia were transplanted into the abdomen of 182 neurulae (Fig. 1A). Ectopic heart was formed in 138 recipients $(75.8 \%)$ and beating of the abdominal heart-like tissue began 1 day after transplantation, simultaneously with the developing host heart (Fig. 1B). At 5 days after transplantation, erythrocytes began flowing into the transplanted heart chambers, with flow readily observed through the transparent epidermis (Supplemental movie 1). The new heart created in the posterior abdomen comprised at least two chambers and participated in the systemic circula-
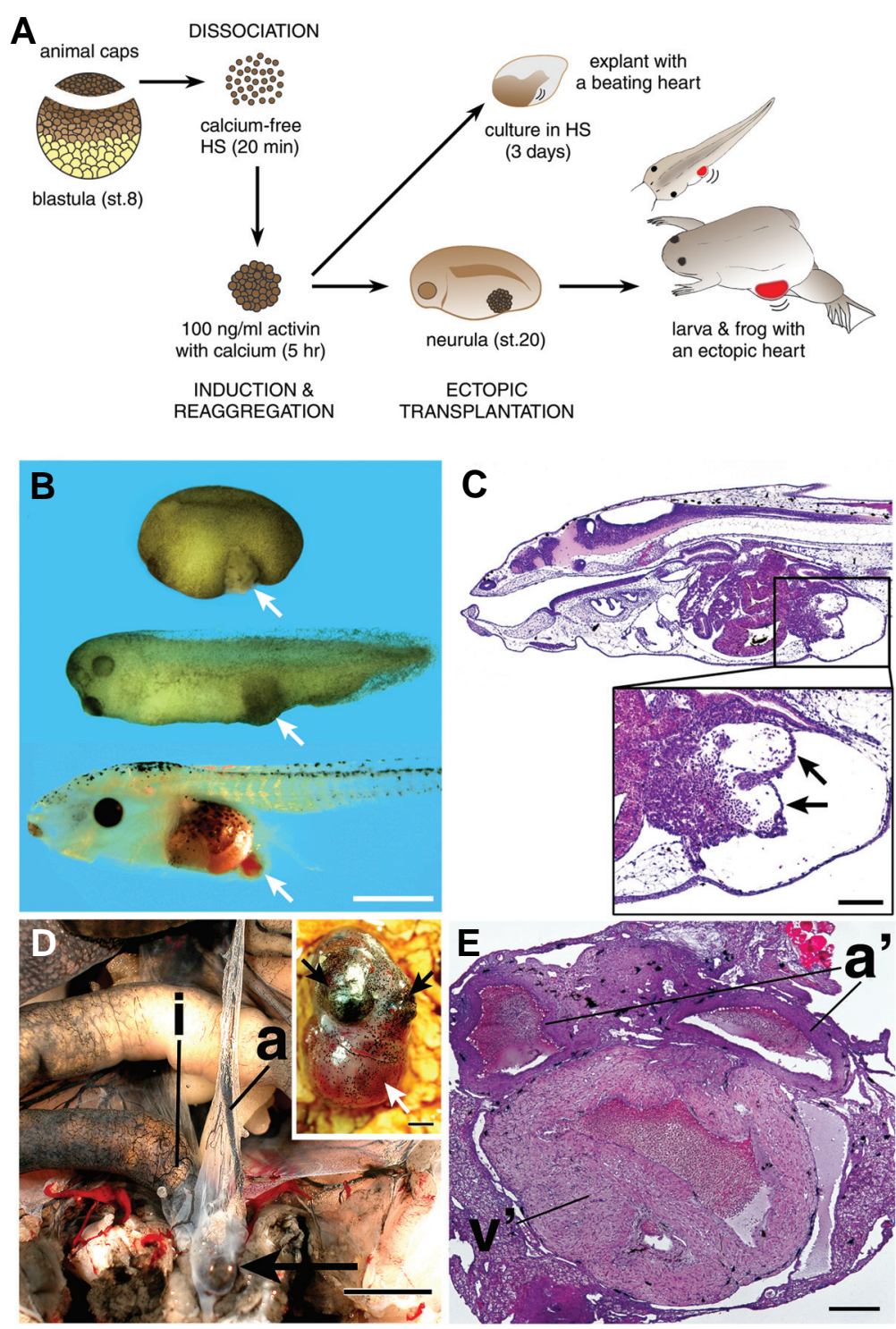

Fig. 1. In vitro cardiomyocyte induction and in vivo ectopic heart formation. (A) Experimental protocol of the in vitro cardiomyocyte induction and ectopic heart transplantation. For further details, see Materials and Methods. (B) External morphology of embryos that received the transplant in the abdomen: top, immediately after transplantation (st. 20); middle, 1 day after transplantation (st. 35); bottom, 5 days after transplantation (st. 46). Transplanted in vitro-induced cardiac primordium started beating on day 1 after transplantation (middle), and erythrocytes were present in the ectopic heart at day 5 (bottom). Arrows indicate the transplants. Scale bar, $1 \mathrm{~mm}$. Also see Supplemental movie 1. (C) Sagittal section of larva at day 5 after transplantation (st. 46). Erythrocytes are visible in the ectopic heart, which is clearly divided into two chambers (arrows). HE staining. Scale bar, $100 \mu \mathrm{m}$. (D) Necropsy photograph of frog abdomen at one year after heart transplantation. Ectopic heart (arrow) is surrounded by epicardium and is present between the intestine (i) and anterior abdominal vein (a). Blood vessels appear black because India ink was injected into the original host heart. Scale bar, $10 \mathrm{~mm}$. Contour of excised ectopic heart (right upper corner). At least 3 chambers can be observed from outside the heart. Contractions start in the upper two chambers (black arrows) and continue to the lower chamber (white arrow). Scale bar, $1 \mathrm{~mm}$. (E) Histological appearance of the excised ectopic heart, showing section of same heart shown in (D). One of the three chambers comprises a thick and deeply penetrating layer of myocardium with ventricle-like morphology $\left(v^{\prime}\right)$. The remaining two chambers are surrounded by a thin layer of myocardium and exhibit atrium-like morphology (a'). HE staining. Scale bar, $200 \mu \mathrm{m}$. 
tion. Histological examination of 20 recipients confirmed the presence of erythrocytes inside the heart chambers formed in the abdomen (Fig. 1C). Approximately $60 \%$ (68 of 118) of recipients developed normally and metamorphosed into adult frogs within the normal time frame of 2 months. The ectopic hearts continued to beat in the adults, with cardiac contraction observable from the abdominal surface (Supplemental movie 2). Further morphological and physiological analyses were carried out on 24 of the 68 adult recipients (aged approximately 1 year), selected at random. Laparotomized frogs were injected with India ink into the ventricle of the host heart. This showed blood flow into the ectopic heart through the mesenteric arteries of the small intestine and out of the ectopic heart to the anterior abdominal vein (Fig. 1D). Excision and macroscopic observation of ectopic hearts revealed chambers with two atrium-like sections and one ventricle-like part, as typical of a normal frog heart (Fig. 1D right-upper corner). Cardiac contractions appeared to originate from the atriumlike sites and continue toward the ventricle-like site. Histological sections showed multiple chambers in the ectopic hearts: a ventricle-like chamber comprising a thick and deeply penetrating layer of myocardium, and two atriumlike chambers surrounded by a thin layer of myocardium (Fig. 1E).

\section{Physiological analyses and echocardiography of the dual-heart frogs}

Electrocardiography (ECG) recordings were obtained from the body surface of frogs to detemine actual rhythms of the host and ectopic hearts and how such rhythms were related. The ECG of normal hearts displayed p-wave (representative of an atrial contraction) and narrow QRS (representative of a ventricular contraction) complexes (Fig. 2A). The ectopic hearts showed no apparent $\mathrm{p}$-waves and wide QRS (QRS' in Fig. 2A) complexes, which persisted after elimination of the host heart (Fig. 2B). The ectopic heart rhythms were regular, with a relatively long cycle, and independent of the host rhythms. Monophasic action potentials from the excised ectopic hearts revealed three different action potentials, resembling those of the sinus nodes, atria, and ventricles of normal heart (Fig. 2C). Two-dimensional echocardiography of the ectopic heart revealed two different chambers with muscular layers of differing thickness, and valve-like structures separating the chambers. Blood flow was observed in each chamber under color Doppler echocardiography (Fig. 3, Supplemental movie 3).
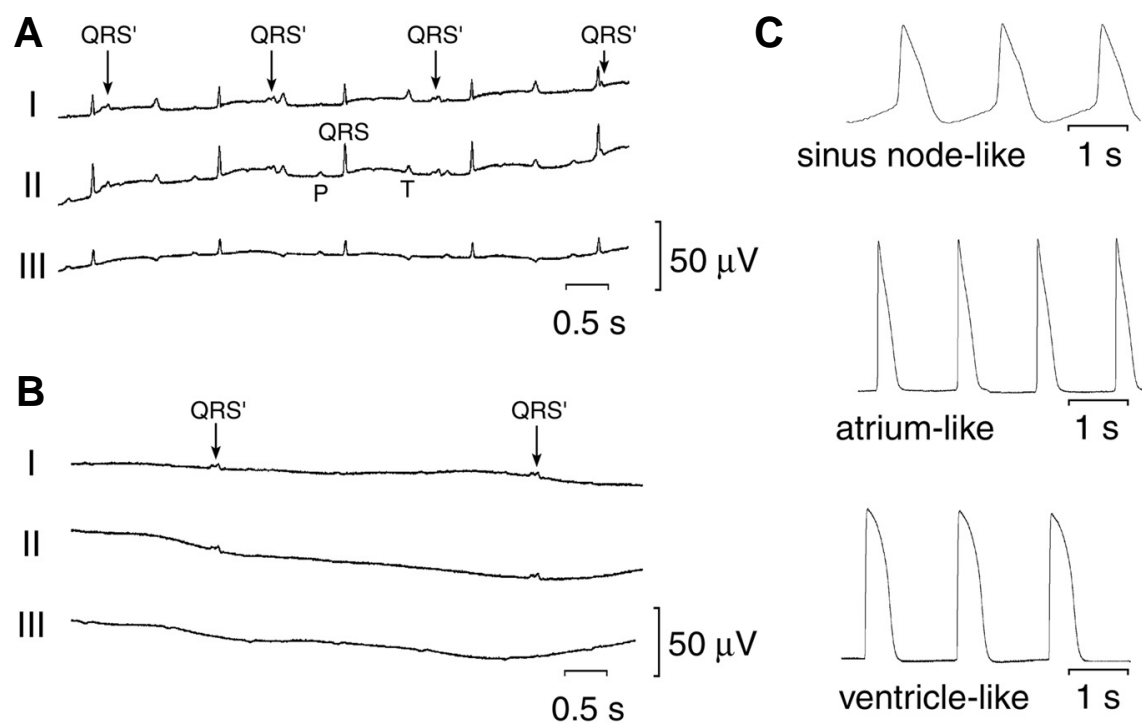

Fig. 2. Physiological analysis of ectopic heart developed from in vitro-induced cardiac primordium. (A) ECG of frog with two hearts. P and QRS indicate host atrial and ventricular potentials, respectively. QRS' indicates ectopic ventricular potential. $T$ is host ventriclar repolarization. (B) ECG after elimination of the host heart. QRS' waveforms remained apparent in the ectopic heart. (C) Action potential in the excised ectopic heart. By changing the measurement site, three types of action potentials were recorded, resembling sinus node, atrial, and ventricular action potentials.
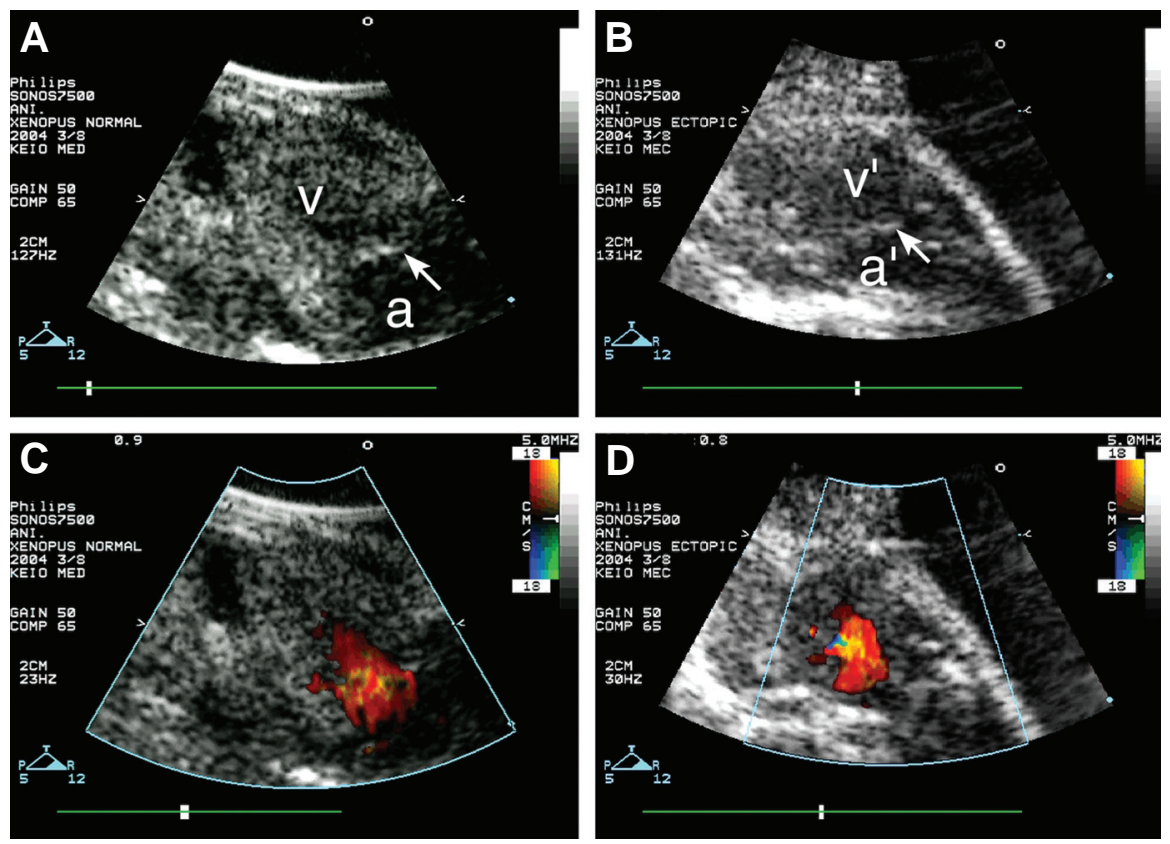

Fig. 3. Echocardiography of the dual-heart frogs. (A) Two-dimensional echocardiogram of normal heart, showing atrium (a) and ventricle (v). Valve-like tissue (arrow) is visible between these two chambers. (B) Two-dimensional echocardiogram of the ectopic heart. As with the normal heart, two chambers are apparent and valve-like tissue (arrow) is visible between the atrium-like ( $\left.a^{\prime}\right)$ and ventricle-like ( $\left.v^{\prime}\right)$ structures. Also see Supplemental movie 3. (C) Color Doppler echocardiography of the normal heart. (D) Color Doppler echocardiography of the ectopic heart. Also see Supplemental movie 3. Blood flow between the two chambers is indicated by color (red, blood flow towards probe; blue, flow in the opposite direction). 

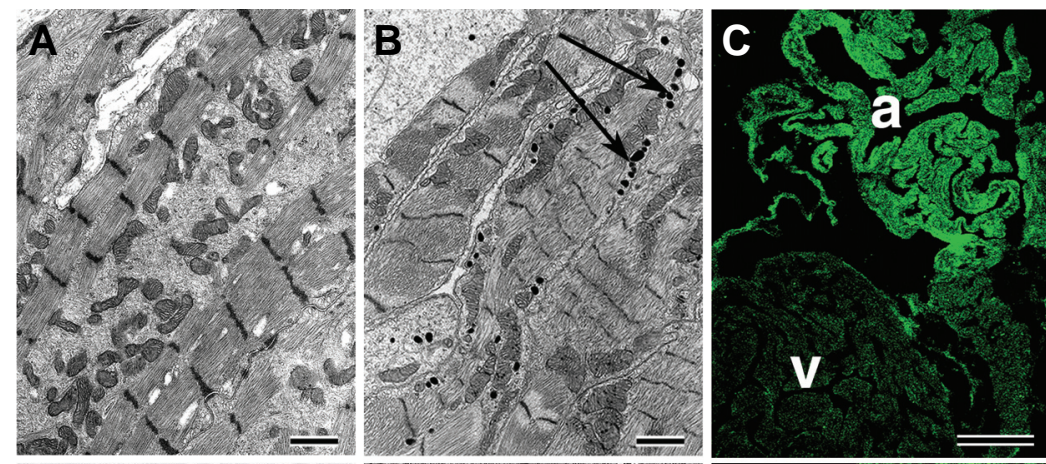

in the realm of tissue engineering. Successful regeneration of a functioning organ requires a means of differentiating cells into a heart complete with higher order structures such as atria and ventricles.

The present investigation assessed an unique induction method developed by us to reliably induce cardiomyocytes with high frequency (Ariizumi et al. 2003). Specifically, the animal cap is dissociated once then reaggregated by treatment with activin. Beating tissues were exclusively formed when myocardial cells induced using this method were cultured. We also recently reported the transient expression of BMP inhibitor noggin
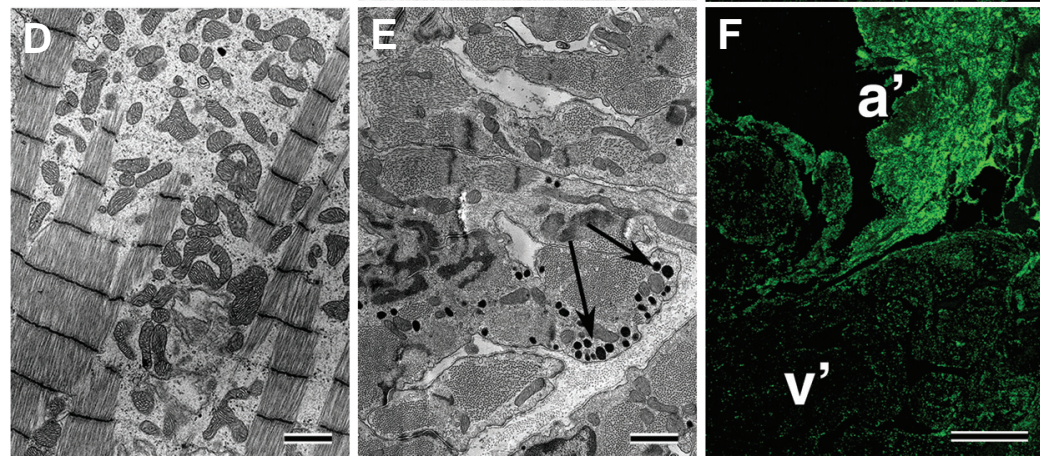

in precardiac mesoderm, and showed that the consequent inhibition of BMP signaling efficiently induced cardiomyocytes from murine ES cells (Yuasa et al. 2005). We postulated that the molecular mechanism of specific cardiomyocyte induction at play in our protocol involved the transient and strong inhibition of intrinsic BMP signals that activate cardiomyocyte induction. The dissociation of animal caps would dilute intrinsic BMP signaling pathways by disrupting cell-cell contacts, followed by the reaggregation and stimulation with activin.

The Xenopus cardiomyocyte induction method might be more widely applicable for analyzing cardiogenesis in vertebrates at the molecular level. It will enable the identification of new genes involved in the earliest stages of cardiogenesis, for which analysis has been difficult in previous experimental systems that use the presumptive cardiac region as source material. The system will also permit more detailed analyses of the roles of growth factors and transcription factors in cardiogenesis (Marvin et al. 2001; Schneider and Melcola, 2001; Flaherty and Dawn 2008; Zhu et al., 2008).

Transplantation of the in vitro-derived cardiac primor-

\section{Electron microscopy and immunohistochemical observa- tions of the heart chambers}

Electron microscopy revealed characteristic cardiac structures in the ectopic hearts including sarcomeres and intercalated discs. Numerous atrial natriuretic peptide (ANP) vesicles were clearly apparent in the atrium-like parts of ectopic hearts, but not in the ventricular myocardial cytoplasm (Fig. 4). These findings strongly indicated that the ectopic heart had two different chambers, atrium and ventricles. Immunofluorescent staining revealed contractile proteins including actin and troponin in the ectopic hearts as in the host organs (data not shown). ANP was more strongly expressed at the atrial myocardium than at ventricles in both the ectopic and normal hearts (Fig. 4).

\section{Discussion}

The successful induction of cardiomyocytes from ES cells sparked vigorous efforts to develop clinical applications. Difficulties persist, however, in creating higher order cardiac structures such as atria and ventricles from ES cells. Current methods to regenerate myocardium involve selecting only those stem cells that have differentiated into cardiomyocytes and transplanting them into infarcted hearts (Caspi et al. 2007; Reinecke et al. 2008). Despite innovations such as transplantation of cardiomyocyte sheets (Shimizu et al. 2009), these efforts remain dia into neurula-stage embryos resulted in complete ectopic heart formation at the abdominal site. The temporal and spatial environment of the recipient tissue is thought to be critical in accepting and maturating the cardiac primordium into a viable ectopic heart. The abdominal site might be successful because (1) the inhibitory signals for cardiomyocyte differentiation were not expressed in this area, (2) major vessels that could connect to the ectopic heart are numerous in this area, (3) space was available in the abdomen for the ectopic heart to establish and grow, and (4) the ectopic heart did not interfere with the host circulatory systems. Transplanted cardiac primordium not only differentiated into a beating heart, but this heart also communicated with the vascular system of the host and was incorporated into the systemic circulation. This system may thus be useful for analyzing the mechanisms of communication between the heart and vasculature. Moreover, transplanted cardiac primordia could be manipulated to undergo morphogenetic processes such as looping and separation of atria and ventricles, and such studies would advance our understanding of inductive interactions with surrounding tissues (Melcola 1999; Takano et al., 2007; Wagner and Siddiqui 2007 a,b).

In this investigation, use of a special method involving transplantation into embryos was attempted. Although this has no immediate clinical applications, the finding that a heart induced in vitrocan form higher-order structures in the body and function as a circulatory organ seems to represent a basic research finding 
that will prove important to the advancement of heart regeneration research.

\section{Materials and Methods}

\section{In vitro cardiomyocyte induction from animal caps}

Cardiomyocyte differentiation was induced in vitrousing animal caps of Xenopus blastulae as described previously (Fig. 1A; Ariizumi et al. 2003). Briefly, embryos were cultured and prepared in Holtfreter's saline as medium (HS: $60 \mathrm{mM} \mathrm{NaCl}, 0.7 \mathrm{mM} \mathrm{KCl}, 0.9 \mathrm{mM} \mathrm{CaCl}_{2}, 4.6 \mathrm{mM}$ HEPES, $0.1 \mathrm{~g} / \mathrm{l}$ kanamycin sulfate, 0.1\% BSA [A-7888, Sigma-Aldrich, St. Louis, MO], $\mathrm{pH}$ 7.6). Human recombinant activin $A$, a peptide growth factor (a gift from Dr. Y. Eto [Central Research Laboratories, Ajinomoto Co, Japan]), was dissolved in HS and used as an inducer. At the midblastula stage (st. 8; Nieuwkoop and Faber 1956), $0.8 \mathrm{~mm} \times 0.8 \mathrm{~mm}$ of the animal cap region was excised using tungsten needles. Animal caps from 5 blastulae were pooled, placed in $100 \mu \mathrm{l}$ of $\mathrm{Ca}^{2+}$-free HS per well of 96well plates with round bottoms (MS-309UR, Sumitomo Bakelite, Tokyo, Japan) and left to stand for 20 min to loosen intercellular adhesions. The solution was then substituted with $100 \mu$ of $\mathrm{HS}\left(\mathrm{Ca}^{2+}\right.$-plus) containing 100 $\mathrm{ng} / \mathrm{ml}$ of activin $A$ and the cells were dissociated by gentle pipetting before being treated in the activin solution for $5 \mathrm{~h}$. Reaggregates formed during this period were cultured in HS.

\section{In vivo transplantation of cardiomyocyte primordium for ectopic heart formation}

For the ectopic transplantation experiment (Fig. 1A), reaggregates were split into appropriate sizes (20-25\% of original) after 1 day of culture. The smaller pieces of reaggregate were then transplanted into an incision made in the abdomens (immediately anterior to the cloaca) of neurulae (st. 20) from the same parent. Embryos that received transplants were allowed to develop and metamorphose into frogs over approximately 2 months, and were then maintained for one year. Beating ectopic (secondary) hearts in the transplanted embryos were subjected to morphological and electrophysiological analysis.

\section{Action potential recording, electrocardiography, two-dimensional,} and Doppler echocardiography

Action potentials in the ectopic hearts were recorded at multiple sites in water at $22^{\circ} \mathrm{C}$ using the patch-clamp method. The heart contractions were too strong to obtain stable recordings using glass microelectrodes, thus action potentials were obtained using suction-type recordings of monophasic action potentials. For electrocardiography, four needle electrodes were inserted into the limbs (left arm, right arm, left leg, and one electrode in the right leg for earthing the current), and limb-lead electrocardiography was conducted at room temperature. Two-dimensional, continuous-wave, and color Doppler echocardiography was performed from the abdominal surface using an Image point 1500 (Philips, USA) with a $15-\mathrm{MHz}$ transducer.

\section{Histological, electron microscopic, and immunohistochemical ob- servations}

Ectopic hearts excised from 1-year-old frogs were fixed in Bouin's fluid, and $6-\mu \mathrm{m}$-thick paraffin sections were prepared using standard procedures. Sections were stained with haematoxylin and eosin to assess tissue differentiation. For electron microscopy, the excised normal and ectopic hearts were fixed using 3\% paraformaldehyde and $2.5 \%$ glutaraldehyde in $0.1 \mathrm{M}$ cacodylate buffer $(\mathrm{pH} 7.4)$, and then post-fixed in $1 \% \mathrm{OsO}_{4}$ in cacodylate buffer. Specimens were dehydrated and embedded in epoxy resin, sectioned, and double-stained using uranyl acetate and lead citrate, for observation under a transmission electron microscope (JEM-100C, JEOL, Tokyo, Japan). For immunohistochemical analysis, excised normal and ectopic hearts were fixed in 4\% paraformaldehyde buffered with PBS $(\mathrm{pH} 7.0)$ at $4^{\circ} \mathrm{C}$ overnight and placed in PBS in which the sucrose concentration was increased to $20 \%$ in a stepwise fashion. Tissues were subsequently embedded in OCT compound, and a cryostat was used to prepare frozen sections at $10-\mu \mathrm{m}$ thickness. Sections were blocked with 10\% goat serum (Jackson ImmunoResearch Laboratories, West Grove, PA) in PBS and incubated with primary antibody dissolved in $10 \%$ goat serum in PBS overnight at $4^{\circ} \mathrm{C}$. A rabbit polyclonal antibody specific for atrial natriuretic peptide (ANP) (AB5490, Chemicon) was used at a dilution of 1:250. After two washes with PBS, sections were incubated for $1 \mathrm{~h}$ at room temperature with Alexa Fluor ${ }^{B}$ 488 goat anti-rabbit IgG (A-11008, Molecular Probes) secondary antibody at a dilution of 1:500. Antibody binding was observed using a confocal laser scanning microscope (Radiance 2100, Japan Bio-Rad Laboratories, Tokyo, Japan).

\section{Acknowledgments}

This study was supported in part by Grants-in-Aid for Scientific Research from the Ministry of Education, Science, Sports and Culture of Japan. T.A. was supported by a research fellowship from the Uehara Memorial Foundation.

\section{References}

ARIIZUMI T, KOMAZAKI S, ASASHIMA M, MALACINSKI GM (1996). Activin treated urodele ectoderm: a model experimental system for cardiogenesis. Int $J$ Dev Bio/40: 715-718

ARIIZUMI T, ASASHIMA M (2001). In vitro induction systems for analyses of amphibian organogenesis and body patterning. Int J Dev Bio/45: 273-279.

ARIIZUMI T, KINOSHITA M, YOKOTA C, TAKANO K, FUKUDA K, MORIYAMA N MALACINSKI GM, ASASHIMA M (2003). Amphibian in vitro heart induction: a simple and reliable model for the study of vertebrate cardiac development. Int $J$ Dev Bio/47: 405-410

ASASHIMA M, MICHIUE T, KURISAKI A (2008). Elucidation of the role of activin in organogenesis using a multiple organ induction system with amphibian and mouse undifferentiated cells in vitro. Dev Growth Differ 50 Suppl 1: S35-45.

ASASHIMA M, ITO Y, CHAN T, MICHIUE T, NAKANISHI M, SUZUKI K, HITACHI K, OKABAYASHI K, KONDOW A, ARIIZUMI T (2009). In vitro organogenesis from undifferentiated cells in Xenopus. Dev Dyn 238: 1309-1320.

CASPI O, HUBER I, KEHAT I, HABIB M, ARBEL G, GEPSTEIN A, YANKELSON $L$, ARONSON D, BEYAR R, GEPSTEIN L (2007). Transplantation of human embryonic stem cell-derived cardiomyocytes improves myocardial performance in infarcted rat hearts. $J$ Am Coll Cardio/50: 1884-1893.

DENGLER TJ, KATUS HA (2002). Stem cell therapy for the infarcted hear («cellular cardiomyoplasty»). Herz 27: 598-610.

FLAHERTYMP, DAWNB (2008). Noncanonical Wnt11 signaling and cardiomyogenic differentiation. Trends Cardiovasc Med 18: 260-268.

FUKUDA K, YUASA S (2006). Stem cells as a source of regenerative cardiomyocytes. Circ Res 98: 1002-1013.

LATINKIC, BV, KOTECHA S, MOHUN TJ (2003). Induction of cardiomyocytes by GATA4 in Xenopus ectodermal explants. Development 130: 3865-3876.

MARVIN MJ, DI ROCCO G, GARDINER A, BUSH SM, LASSAR AB (2001). Inhibition of Wnt activity induces heart formation from posterior mesoderm. Genes Dev 15: 316-327.

MAURITZ C, SCHWANKE K, REPPEL M, NEEF S, KATSIRNTAKI K, MAIER LS NGUEMO F, MENKE S, HAUSTEIN M, HESCHELER J, HASENFUSS G, MARTIN U (2008). Generation of functional murine cardiac myocytes from induced pluripotent stem cells. Circulation 118: 507-517.

MERCOLA M (1999). Embryological basis for cardiac left-right asymmetry. Semin Cell Dev Biol 10: 109-116.

NIEUWKOOP PD, FABER J (1956). Normal Table of Xenopus laevis (Daudin). North Holland, Amsterdam.

PANDUR P, LÄSCHE M, EISENBERG LM, KÜHL M (2002). Wnt-11 activation of a non-canonical Wnt signalling pathway is required for cardiogenesis. Nature 418: $636-641$

REINECKE H, MINAMI E, Zhu WZ, LAFLAMME MA (2008). Cardiogenic differ- 
entiation and transdifferentiation of progenitor cells. Circ Res 103: 1058-1071.

SCHNEIDER VA, MERCOLA M (2001). Wnt antagonism initiates cardiogenesis in Xenopus laevis. Genes Dev 15: 304-315.

SHIMIZU T, SEKINE H, YAMATO M, OKANO T (2009). Cell sheet-based myocardial tissue engineering: new hope for damaged heart rescue. Curr Pharm Des 15: $2807-2814$

TAKANO, K., ITO, Y., OBATA, S., OINUMA, T., KOMAZAKI, S., NAKAMURA, H. and ASASHIMA, M. (2007). Heart formation and left-right asymmetry in separated right and left embryos of a newt. Int. J. Dev. Biol. 51: 265-272.

WAGNER M, SIDDIQUI MA (2007a). Signal transduction in early heart development (I): cardiogenic induction and heart tube formation. Exp BiolMed (Maywood) 232: 852-865.
WAGNER M, SIDDIQUI MA (2007b). Signal transduction in early heart development (II): ventricular chamber specification, trabeculation, and heart valve formation. Exp Biol Med (Maywood) 232: 866-880.

WARKMAN AS, KRIEG PA (2007). Xenopusas a model system for vertebrate heart development. Semin Cel/ Dev Biol18: 46-53.

YUASA S, ITABASHIY, KOSHIMIZUU, TANAKA T, SUGIMURA K, KINOSHITAM, HATTORI F, FUKAMI S, SHIMAZAKI T, OGAWA S, OKANO H, FUKUDA K (2005). Transient inhibition of BMP signaling by Noggin induces cardiomyocyte differentiation of mouse embryonic stem cells. Nat Biotechno/23: 607-611.

ZHUW, SHIOJIMA I, ITOY, LIZ, IKEDA H, YOSHIDA M, NAITO AT, NISHI J, UENO $H$, UMEZAWA A, MINAMINO T, NAGAIT, KIKUCHI A, ASASHIMA M, KOMURO I (2008). IGFBP-4 is an inhibitor of canonical Wnt signalling required for cardiogenesis. Nature 454: 345-349.

\section{Further Related Reading, published previously in the Int. J. Dev. Biol.}

See our recent Special Issue Placenta edited by Joan S. Hunt and Kent L. Thornburg at: http://www.ijdb.ehu.es/web/contents.php?vol=54\&issue=2-3

See our related Special Issue Developmental Morphodynamics edited by Lev Beloussov and Richard Gordon at:

http://www.ijdb.ehu.es/web/contents.php?vol=50\&issue=2-3

Heart formation and left-right asymmetry in separated right and left embryos of a newt Kazuhiro Takano, Yuzuru Ito, Shuichi Obata, Tsutomu Oinuma, Shinji Komazaki, Hiroaki Nakamura and Makoto Asashima

Int. J. Dev. Biol. (2007) 51: 265-272

Amphibian in vitro heart induction: a simple and reliable model for the study of vertebrate cardiac development

Takashi Ariizumi, Masayoshi Kinoshita, Chika Yokota, Kazuhiro Takano, Keiichi Fukuda, Nobuo Moriyama, George M Malacinski and Makoto Asashima

Int. J. Dev. Biol. (2003) 47: 405-410

In vitro induction systems for analyses of amphibian organogenesis and body patterning. T Ariizumi and M Asashima

Int. J. Dev. Biol. (2001) 45: 273-279

Amphibian embryos as a model system for organ engineering: in vitro induction and rescue of the heart anlage.

H Grunz

Int. J. Dev. Biol. (1999) 43: 361-364

Activin treated urodele ectoderm: a model experimental system for cardiogenesis. T Ariizumi, S Komazaki, M Asashima and G M Malacinski Int. J. Dev. Biol. (1996) 40: 715-718

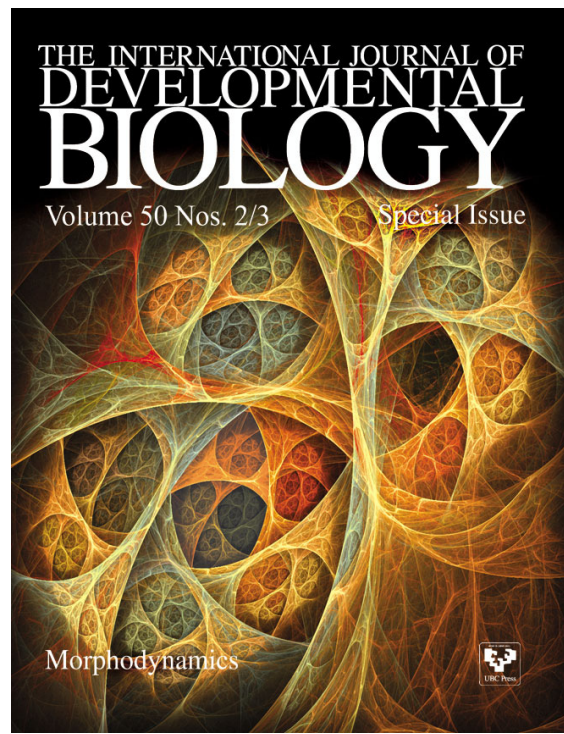

5 yr ISI Impact Factor $(2008)=3.271$

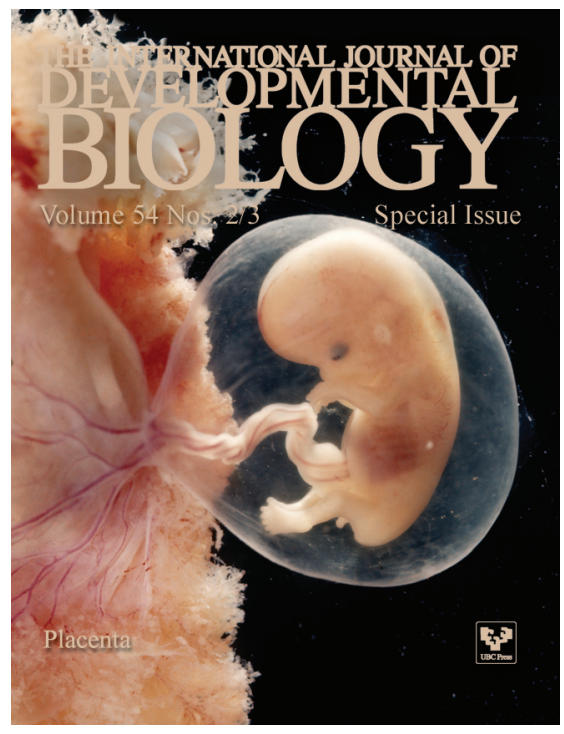

